\title{
Cognitive performances in patients affected by late-onset epilepsy with unknown etiology: A 12-month follow-up study
}

\author{
Claudio Liguori ${ }^{\mathrm{a}, *}$, Cinzia Costa $^{\mathrm{b}}$, Flaminia Franchini ${ }^{\mathrm{d}}$, Francesca Izzi ${ }^{\mathrm{a}}$, Matteo Spanetta ${ }^{\mathrm{a}}$, Elena Nardi Cesarini ${ }^{\mathrm{b}}$, \\ Simona Di Santo ${ }^{c}$, Natalia Manfredi ${ }^{a}$, Lucia Farotti ${ }^{b}$, Michele Romoli ${ }^{\text {b,c }}$, Alessandro Lanari ${ }^{\mathrm{b}}$, Nicola Salvadori ${ }^{\mathrm{b}}$, \\ Lucilla Parnetti ${ }^{\text {b }}$, Paolo Calabresi ${ }^{\text {b,d }}$, Nicola Biagio Mercuri ${ }^{\text {a,d }}$, Fabio Placidi ${ }^{\text {a }}$ \\ a Epilepsy Centre, Neurophysiopathology Unit, Department of Systems Medicine, University of Rome "Tor Vergata", Rome, Italy \\ ${ }^{\mathrm{b}}$ Neurology Clinic, University of Perugia - S. Maria della Misericordia Hospital, Perugia, Italy \\ c Neurology Unit, Department of Medicine, Rimini “Infermi" Hospital - AUSL Romagna, Italy \\ d IRCCS Fondazione Santa Lucia, Rome, Italy
}

\section{A R T I C L E I N F O}

\section{Article history:}

Received 13 July 2019

Revised 18 September 2019

Accepted 23 September 2019

Available online 11 November 2019

\section{Keywords:}

Cognition

Late-onset epilepsy

Seizures

Antiepileptic drugs

\begin{abstract}
A B S T R A C T
Introduction: Epilepsy has a growing frequency, particularly in the elderly. Several triggers may cause late-onset epilepsy; however, more than $20 \%$ of epilepsies, manifesting in the elderly, has an unknown etiology. Although cognition is frequently altered in patients affected by epilepsy, there is a paucity of studies specifically evaluating cognition in patients affected by late-onset epilepsy. The aim of the present study was to assess the cognitive profile of patients affected by late-onset epilepsy with an unknown etiology and followed for 12 months.

Methods: Patients affected by diagnosed late-onset epilepsy with unknown etiology were included in this observation. All patients were evaluated at the time of diagnosis (baseline) and at follow-up (12 months later). We distributed patients in subgroups based on seizure type (focal seizures [FS], secondarily generalized seizures [SGS], primarily generalized seizures [GS]) and antiepileptic drug (AED) regimen (mono- vs. polytherapy). Cognition was evaluated through standardized neuropsychological testing.

Results: Fifty-eight patients were included in this observation and distributed in three groups: 29 affected by FS, 14 affected by SGS, 15 affected by GS. Forty-five patients were in monotherapy, and 13 in polytherapy. The most frequent treatments were levetiracetam $(n=12)$, valproic acid (VPA) $(n=9)$, carbamazepine $(n=9)$, and oxcarbazepine $(n=7)$. We documented a significant decrease of Mini-Mental State Examination (MMSE) and memory scores at follow-up in the whole group. Verbal learning decreased exclusively in VPA users.

Conclusion: Patients affected by late-onset epilepsy with unknown etiology showed a significant decline of cognition at follow-up, independently from number and efficacy of AEDs received. These results deserve verification in larger longitudinal cohorts.
\end{abstract}

(c) 2019 Elsevier Inc. All rights reserved.

\section{Introduction}

The prevalence of epilepsy increases steadily after the age of 55 years $[1,2]$. As life expectancy increases, with the population older than 65 years projected to grow by $60 \%$ in the next 15 years, the burden of late-onset epilepsy (LOE) is expected to increase [3]. Several causes might underlie LOE, including stroke, which accounts for up to $50 \%$ of cases, head trauma, metabolic diseases, structural lesions, dementia, or autoimmunity [4]. However, despite standard diagnostic workflow, more than $20 \%$ of LOE may present with an unknown etiology $[2,3,5]$. Several hypotheses at the basis of this late-onset epilepsy with

\footnotetext{
* Corresponding author at: Epilepsy Centre, Neurology Unit, Department of Systems Medicine, University of Rome "Tor Vergata", Viale Oxford 81, 00133 Rome, Italy.

E-mail address: dott.claudioliguori@yahoo.it (C. Liguori).
}

unknown origin (LOEU) have been postulated, with some clinical and preclinical studies suggesting that epileptic activity can be related to pathophysiological processes similar to those responsible for dementia, including dysregulation of cerebral $\beta$-amyloid and tau metabolism and inflammatory responses [1,5,6].

Despite a possible association of epilepsy with cognitive decline, we still have minimal understanding on factors influencing the trajectory of cognitive decline among patients with epilepsy [4]. This is particularly true for patients with LOEU, for which we have to date no clue on the impact of seizure semiology and antiepileptic drug (AED) regimen on cognitive decline. Hence, we set up a prospective study aimed at the following: i) investigating the cognitive status of patients affected by LOEU over 12 months after diagnosis; ii) evaluating the response of LOEU to the AEDs; iii) investigating the possible cognitive effects of AEDs at follow-up in this population of patients. 
Table 1

Demographic and clinical data of patients included in the study.

\begin{tabular}{|c|c|c|c|c|c|}
\hline & $\begin{array}{l}\text { Group }(\mathrm{n}=58) \\
(\text { mean } \pm S D)\end{array}$ & $\begin{array}{l}\mathrm{FS}(\mathrm{n}=29) \\
(\text { mean } \pm \text { SD })\end{array}$ & $\begin{array}{l}\mathrm{SGS}(\mathrm{n}=14) \\
(\text { mean } \pm \mathrm{SD})\end{array}$ & $\begin{array}{l}\mathrm{GS}(\mathrm{n}=15) \\
(\text { mean } \pm \mathrm{SD})\end{array}$ & $\mathrm{p}$ value \\
\hline Age (years) & $\begin{array}{l}64.7 \pm 9.5 \\
(55-80)\end{array}$ & $\begin{array}{l}65.7 \pm 9.07 \\
(55-80)\end{array}$ & $\begin{array}{l}63.07 \pm 10.22 \\
(56-74)\end{array}$ & $\begin{array}{l}61.8 \pm 10.05 \\
(56-78)\end{array}$ & NS \\
\hline Sex & $27 \mathrm{~F} 31 \mathrm{M}$ & $18 \mathrm{~F} 11 \mathrm{M}$ & $4 \mathrm{~F} 10 \mathrm{M}$ & $5 \mathrm{~F} 10 \mathrm{M}$ & NS \\
\hline Monotherapy & $\begin{array}{l}45 \\
12 \mathrm{LEV}\end{array}$ & 19 & 12 & 14 & NS \\
\hline AEDs & $\begin{array}{l}9 \mathrm{CBZ} \\
9 \mathrm{VPA} \\
70 \mathrm{XC} \\
4 \mathrm{LTG} \\
2 \mathrm{~PB} \\
1 \mathrm{TPM} \\
1 \mathrm{ZNS}\end{array}$ & $\begin{array}{l}7 \mathrm{CBZ} \\
50 X C \\
5 \mathrm{LEV}, \\
1 \mathrm{LTG}, \\
1 \mathrm{ZNS}\end{array}$ & $\begin{array}{l}3 \mathrm{VPA}, \\
3 \mathrm{LEV}, \\
2 \mathrm{LTG} \\
2 \mathrm{OXC} \\
2 \mathrm{CBZ}\end{array}$ & $\begin{array}{l}6 \mathrm{VPA}, \\
4 \mathrm{LEV}, \\
2 \mathrm{~PB}, \\
1 \mathrm{TPM}, \\
1 \mathrm{LTG}\end{array}$ & NA \\
\hline Polytherapy & 13 & 10 & 2 & 1 & NS \\
\hline Follow-up data & & & & & \\
\hline Seizure reduction $\geq 50 \%$ & $11(19 \%)$ & $9(27 \%)$ & $0(0 \%)$ & $2(13 \%)$ & NS \\
\hline Seizure freedom & 47 (81\%) & $20(65 \%)$ & $14(100 \%)$ & $13(87 \%)$ & NS \\
\hline
\end{tabular}

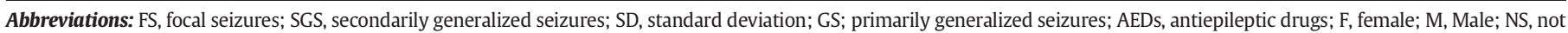

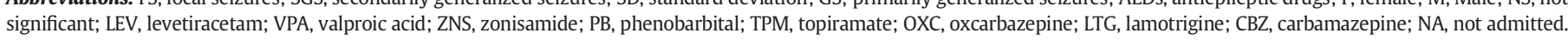

\section{Methods}

The present report is a prospective observational study including patients aged $>55$ years old, with diagnosed LOEU at the Epilepsy Centers of the University Hospital of Rome "Tor Vergata" and S. Maria della Misericordia Hospital in Perugia. The cutoff of 55 was chosen based on the previous literature about LOEU [1]. Data were collected from January 2015 to June 2018 by the two centers. All patients, with diagnosed LOEU, underwent a standard neuropsychological evaluation at baseline (before AED treatment), which was repeated at the 12-month follow-up visit. Patients were classified according to the 1981 International League Against Epilepsy, which was in use when the patients were evaluated $[7,8]$. Inclusion criteria were as follows: continuative treatment with antiepileptic therapy (either monotherapy or polytherapy) during the study period, availability of epilepsy diary to monitor seizures, Mini-Mental State Examination (MMSE) score $>24$ at the baseline. Exclusion criteria were known causes of epilepsy (including stroke, cerebrovascular disease, head trauma, metabolic diseases, tumor, autoimmunity, history of or ongoing alcohol use), medical history of major psychiatric disorders or other significant neurological diseases (including dementia diagnosis), occurrence of

Table 2

Demographic and clinical data of LOEU-mono and LOEU-poly.

\begin{tabular}{|c|c|c|c|}
\hline & $\begin{array}{l}\text { Monotherapy }(\mathrm{n}=45) \\
(\text { mean } \pm S D)\end{array}$ & $\begin{array}{l}\text { Polytherapy }(n=13) \\
(\text { mean } \pm \text { SD) }\end{array}$ & $\mathrm{p}$ value \\
\hline Age (years) & $\begin{array}{l}62.61 \pm 8.93 \\
(55-80)\end{array}$ & $\begin{array}{l}71.61 \pm 8.57 \\
(59-68)\end{array}$ & $<0.05$ \\
\hline Sex & $20 \mathrm{~F} 25 \mathrm{M}$ & $\begin{array}{l}7 \mathrm{~F} 6 \mathrm{M} \\
2 \mathrm{LEV}+\mathrm{LCM}\end{array}$ & NS \\
\hline AEDs & $\begin{array}{l}\text { 12LEV } \\
9 \mathrm{CBZ} \\
9 \mathrm{VPA} \\
70 X \mathrm{X} \\
4 \mathrm{LTG} \\
2 \mathrm{~PB} \\
1 \mathrm{TPM} \\
1 \mathrm{ZNS}\end{array}$ & $\begin{array}{l}2 \mathrm{LTG}+\mathrm{LEV}, \\
2 \mathrm{VPA}+\mathrm{TPM}, \\
1 \mathrm{VPA}+\mathrm{LEV}, \\
1 \mathrm{VPA}+\mathrm{PER}, \\
1 \mathrm{LEV}+\mathrm{GBP}, \\
1 \mathrm{LEV}+\mathrm{ZNS} \\
1 \mathrm{LEV}+\mathrm{CBZ} \\
1 \mathrm{LEV}+\mathrm{ESL} \\
1 \mathrm{LCM}+\mathrm{ZNS}\end{array}$ & NA \\
\hline Seizure-free & 40 & 7 & NS \\
\hline Seizure reduction $\geq 50 \%$ & 5 & 6 & NS \\
\hline
\end{tabular}

Abbreviations: SD, standard deviation; AEDs, Antiepileptic drugs; F, female; M, Male; NS, not significant; LEV, levetiracetam; VPA, valproic acid; ZNS, zonisamide; PB, phenobarbital; TPM, topiramate; OXC, oxcarbazepine; LTG, lamotrigine; CBZ, carbamazepine; PER; perampanel; ESL, eslicarbazepine; NA, not admitted. seizures in the same day of the neuropsychological evaluation, and brain abnormalities at magnetic resonance imaging (MRI) scan (including hippocampal sclerosis and small vessel disease with Fazekas score $>1$ ).

The neuropsychological battery included a screening test for cognitive global evaluation (MMSE) [9] and an extensive neuropsychological battery assessing different cognitive domains (episodic verbal memory, visual-constructive praxia, language, and executive functions). The tests were chosen according to their reliability and sensitivity of use, following the common clinical practice in patients affected by cognitive decline or epilepsy $[9,10]$.

For evaluation of verbal learning and memory recovery, the Rey Auditory Verbal Learning Test (RAVLT) [11] was used. This test is divided in two parts: Immediate Recall (RAVLT-I) and Delayed (RAVLTD) Recall. In the Immediate Recall, the examiner reads 15 words, at a one-word-per-second pace, and asks the patient to repeat all the memorized words in the patient's preferred order. This task is performed for 5 times in a row, and it is possible to have information about the episodic verbal memory, the encoding and the learning strategies. For the evaluation of the long-term memory (RAVLT-D), the patient is asked to repeat the memorized words from the same 15 -words list, after $15 \mathrm{~min}$. In the meantime, between the Immediate and the Delayed Recall tests, a nonverbal and visuospatial test was administered, in order to avoid any interference with the memory processes.

We chose "The Rey-Osterrieth Complex Figure" Test (ROCF) [12], a complex figure that is shown to the subject who has to copy it on white paper. The copy of ROCF is used for the evaluation of visuoconstructive praxia in patients affected by epilepsy [13] and in patients with Alzheimer's Disease (AD) [14]; moreover, the qualitative analysis of the same test can be useful to detect planning and executive abilities [15].

Thereafter, the capacity of verbal production and cognitive flexibility has been evaluated with the "Phonologic Verbal Fluency" (PVF) test, and the lexical/semantic access has been evaluated with the "Semantic Verbal Fluency" (SVF) test. The assignment to the subject is to enunciate all the words in his mind starting with a specified letter (phonologic criterion) or part of a specific category (semantic criterion), in $1 \mathrm{~min}$. Every minute a different letter or category have been provided, for a total of $6 \mathrm{~min}: 3 \mathrm{~min}$ for the phonological fluency and $3 \mathrm{~min}$ for the semantic fluency.

This study was approved by the local Ethics Committees of both Epilepsy Centers participating to the study, and all the patients included signed the informed consent. 
Table 3

Demographic and clinical data of patients' treatment subgroups.

\begin{tabular}{|c|c|c|c|c|c|}
\hline & $\begin{array}{l}\operatorname{LEV}(\mathrm{n}=12) \\
\text { mean }[\mathrm{SD}]\end{array}$ & $\begin{array}{l}\operatorname{VPA}(\mathrm{n}=9) \\
\text { mean }[\mathrm{SD}]\end{array}$ & $\begin{array}{l}\mathrm{CBZ}(\mathrm{n}=9) \\
\text { mean }[\mathrm{SD}]\end{array}$ & $\begin{array}{l}\text { OXC }(n=7) \\
\text { mean }[S D]\end{array}$ & $\mathrm{p}$ value \\
\hline Age (years) & $\begin{array}{l}65.3[8.27] \\
(55-80)\end{array}$ & $\begin{array}{l}61[9.95] \\
(55-78)\end{array}$ & $\begin{array}{l}60[9.55] \\
(55-80)\end{array}$ & $\begin{array}{l}61.71[9.05] \\
(57-74)\end{array}$ & NS \\
\hline Sex & $5 F 7 M$ & $3 \mathrm{~F} 6 \mathrm{M}$ & $4 \mathrm{~F} 5 \mathrm{M}$ & $4 \mathrm{~F} 3 \mathrm{M}$ & NS \\
\hline Mean dosage (mg/day) & 1500 [476.7] & 833.33 [234.52] & 555.56 [133.33] & $985.71[146.38]$ & NS \\
\hline Seizure-free & 10 & 9 & 9 & 5 & NS \\
\hline Seizure reduction $>50 \%$ & 2 & 0 & 0 & 2 & NS \\
\hline
\end{tabular}

Abbreviations: SD, standard deviation; F, female; M, Male; NS, not significant; LEV, levetiracetam; VPA, valproic acid; OXC, oxcarbazepine; CBZ, carbamazepine.

\subsection{Statistical analysis}

The statistical analysis was performed using commercial software Statistica 10.0 program, Statsoft Inc., Tulsa, OK, USA [16]. Descriptive data were expressed as mean and standard deviation for quantitative analyses. The one-way analysis of variance (ANOVA), using age as covariate, was used to compare descriptive data among the groups, and $\mathrm{p}$ value was set at $\mathrm{p}<.05$ for statistical significance. The paired $t$-test was used to compare data between baseline and follow-up in each subgroup of patients.

\section{Results}

\subsection{Study population}

Overall, 58 patients with LOEU were included (demographic data in Table 1). Twenty-nine patients presented focal seizures (FS), 14 patients secondarily generalized seizures (SGS), and 15 primarily generalized seizures (GS) (Table 1). Forty-five patients at the 12-month follow-up were treated by a first monotherapy (LOEU-mono), and 13 were treated by a polytherapy of 2 AEDs (LOEU-poly) (Table 2). Clinical features and demographic data were equally distributed among seizure semiology and treatment groups, except for the mean age that was higher in the LOEU-poly than LOEU-mono (Table 2). All patients were seizure-free at follow-up or presented a significant reduction of seizures $(\geq 50 \%)$ as reported in Table 1. Levetiracetam (LEV), valproic acid (VPA), carbamazepine (CBZ), and oxcarbazepine (OXC) were the most commonly used AEDs in LOEU-mono group of patients. We also compared the subgroups of patients treated by LEV $(\mathrm{n}=12)$, VPA $(\mathrm{n}=9), \operatorname{CBZ}(\mathrm{n}=9)$, and OXC $(\mathrm{n}=7)$, without finding significant differences (Table 3 ).

\subsection{Longitudinal analysis}

Considering the whole group of patients and comparing the neuropsychological data between baseline and follow-up, we documented a significant reduction of the MMSE score over time for the whole cohort (Table 4). Moreover, at follow-up, the whole cohort had reduced
RAVLT-I scores and slightly higher PVF scores (Table 4). Taking into account the patients' subgroups, we documented significant reduction at follow-up of the MMSE score exclusively in patients affected by FS, and not in the subgroups of patients affected by SGS or GS (Table 4). Patients from the groups with SGS or GS showed a significant increase of PVF, whereas patients affected by FS did not present significant changes of PVF scores. A significant reduction of RAVLT-I scores has been observed in the group with FS (Table 4).

Comparing baseline and follow-up scores both in mono- and polytherapy groups, patients showed a nonsignificant reduction in MMSE and RAVLT-I scores at follow-up (Table 5). Variations in MMSE and RAVLT-I did not reach statistical significance probably because of small sample size, which also limited drug-to-drug comparisons. Nevertheless, LEV, VPA, and CBZ were all associated with a slight reduction of MMSE at follow-up compared to baseline, while OXC was the only AED associated with an increase on MMSE score at follow-up. Interestingly, patients under VPA treatment showed significant reduction of RAVLT-D scores (Table 6).

\section{Discussion}

Despite standard diagnostic procedures, more than $20 \%$ of patients with LOE remain with unknown etiology (LOEU) [2]. Among several mechanisms proposed to underlie epileptogenesis in late adulthood, subtle microvascular changes and beta-amyloid pathology might concurrently participate in cognitive decline among patients with LOEU $[1,3,4]$. However, risk factors for cognitive decline among patients with LOEU are still largely elusive $[1,4,17,18]$. In this study, throughout longitudinal neuropsychological testing, we documented cognitive changes in a prospective cohort of patients affected by LOEU in order to track down and quantify the trajectory of cognition, and to define a possible impact of clinical features or AED management on cognitive decline.

The main result of this study is the identification of global changes in cognition over time among patients with LOEU. Interestingly, the reduction in MMSE scores, a marker of global cognition, was evident in patients affected by FS rather than in those presenting GS. This result is in line with a previous report, which underlined cognitive deterioration after 12 months in patients with diagnosed FS [19], supporting

Table 4

Longitudinal cognitive data of patients divided in subgroups on the basis of seizures semiology.

\begin{tabular}{|c|c|c|c|c|c|c|c|c|}
\hline & \multicolumn{2}{|c|}{$\begin{array}{l}\text { Group }(\mathrm{n}=58) \\
\text { mean }[\mathrm{SD}]\end{array}$} & \multicolumn{2}{|l|}{$\begin{array}{l}\mathrm{FS}(\mathrm{n}=29) \\
\text { mean }[\mathrm{SD}]\end{array}$} & \multicolumn{2}{|l|}{$\begin{array}{l}\mathrm{SGS}(\mathrm{n}=14) \\
\text { mean }[\mathrm{SD}]\end{array}$} & \multicolumn{2}{|l|}{$\begin{array}{l}\mathrm{GS}(\mathrm{n}=15) \\
\text { mean }[\mathrm{SD}]\end{array}$} \\
\hline & Baseline & FU & Baseline & FU & Baseline & $\mathrm{FU}$ & Baseline & FU \\
\hline MMSE & $27.91[1.94]$ & $27.51[2.11]^{*}$ & 28 [2.07] & $27.34[2.17]^{*}$ & 27.29 [1.98] & $27.14[2.28]$ & $28.33[1.63]$ & $28.2[1.78]$ \\
\hline PVF & 25.74 [8.08] & $27.41[9.03]^{*}$ & $25.90[5.59]$ & 25.21 [6.78] & $25.29[12.40]$ & $30.36[13.19]^{*}$ & $25.87[7.77]$ & $29[7.57]^{*}$ \\
\hline SVF & 32.89 [7.80] & $32.56[7.81]$ & $33[7.09]$ & $32.46[7.80]$ & $32.5[10.38]$ & $32.07[8.68]$ & $33.07[6.81]$ & $33.2[7.50]$ \\
\hline RAVLT-I & 29.14 [7.59] & $28.49[8.07]^{*}$ & $28.62[6.76]$ & $27.24[7.43]^{*}$ & 28.14 [9.39] & $29.43[9.02]$ & 31.07 [7.47] & $30.14[8.56]$ \\
\hline RAVLT-D & $4.79[2.37]$ & $4.78[2.01]$ & $5.21[2.04]$ & $4.82[1.77]$ & $3.29[2.40]$ & $4.64[2.40]^{*}$ & $5.4[2.50]$ & $4.86[2.18]$ \\
\hline ROCF & 33.17 [2.37] & $32.26[3.09]$ & $33.17[2.54]$ & 32.17 [3.77] & $32.43[2.38]$ & $31.86[2.60]$ & 33.87 [1.92] & 32.8 [1.90] \\
\hline
\end{tabular}

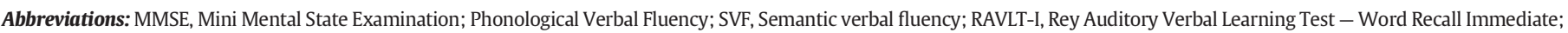
RAVLT-D, Rey Auditory Verbal Learning Test - Word Recall Delayed; ROCF, Rey-Osterrieth Complex Figure Test; SD, standard deviation; FU, follow-up.

* $\mathrm{p}<.05$ 
Table 5

Longitudinal cognitive data of patients under monotherapy or polytherapy.

\begin{tabular}{llllll}
\hline & \multicolumn{2}{l}{$\begin{array}{l}\text { Monotherapy }(\mathrm{n}=45) \\
\text { mean }[S D]\end{array}$} & & \multicolumn{2}{l}{$\begin{array}{l}\text { Polytherapy }(\mathrm{n}=13) \\
\text { mean }[\mathrm{SD}]\end{array}$} \\
\cline { 2 - 3 } \cline { 5 - 6 } & Baseline & FU & & Baseline & FU \\
\hline MMSE & $28.14[1.71]$ & $27.89[1.94]$ & & $27[2.49]$ & $26.15[2.23]$ \\
PVF & $25.34[8.52]$ & $27.77[9.50]^{*}$ & & $27.38[6.74]$ & $26.77[7.73]$ \\
SVF & $33.51[7.61]$ & $33.30[7.12]$ & & $30.31[8.30]$ & $29.54[9.53]$ \\
RAVLT-I & $29.02[7.80]$ & $28.67[8.41]$ & & $28.69[5.86]$ & $27.23[7.00]$ \\
RAVLT-D & $4.52[2.32]$ & $4.77[1.90]$ & & $5.31[2.17]$ & $4.54[2.14]$ \\
ROCF & $33.35[2.19]$ & $32.66[2.58]$ & & $32.46[2.93]$ & $30.92[4.35]$ \\
\hline
\end{tabular}

Abbreviations: MMSE, Mini Mental State Examination; Phonological Verbal Fluency; SVF, Semantic verbal fluency; RAVLT-I, Rey Auditory Verbal Learning Test - Word Recall Immediate; RAVLT-D, Rey Auditory Verbal Learning Test - Word Recall Delayed; ROCF, Rey-Osterrieth Complex Figure Test; SD, standard deviation; FU, follow-up.

$* \mathrm{p}<.05$

the hypothesis of a possible "Accelerate Cognitive Aging" [20] among adult patients with epilepsy. Our finding adds to the available literature, since previous study did not focus on LOEU, but included all patients with FS, independently from etiology or temporal lobe epilepsy specific diagnosis, limiting the reproducibility of results. Moreover, the lack of standardized neuropsychological testing hindered variations in specific cognitive domains over time. Hence, our findings are pivotal to discriminate the evolution of cognitive domains in patients with LOEU, which are for the first time under the spotlight for their cognitive performances. In particular, despite a general cognitive decline, our findings suggest an increase in language abilities and verbal fluency. This finding may represent the beneficial effect of AED treatment, which can reduce seizures and both ictal and interictal electroencephalographic discharges and thus might improve network stability [21]. Patients with Alzheimer's disease and seizures can show accelerated cognitive decline and might stand to benefit from antiepileptic treatments [21]. Hence, our results are in line with previous studies suggesting improvement with antiepileptic treatments in patients with treatment-naïve epilepsy in some cognitive domains, including language [4].

By considering the antiepileptic treatment started by patients affected by LOEU, we more frequently prescribed LEV, VPA, CBZ, or OXC and thus considered these subgroups of patients in the follow-up analysis. Quite surprisingly, a slight reduction in MMSE scores was independent from treatment (except for OXC), once again suggesting a particular susceptibility of LOEU to cognitive decline rather than a cognitive drawback of AED treatment. At the same time, a trend towards higher absolute reduction in MMSE scores was detected with LEV, a finding that warrants further investigation on larger samples. Overall, a key message is that polytherapy does not imply a worse impact on cognitive performance over time when compared to monotherapy, which however was associated with improvement in verbal fluency. Comparing baseline and follow-up scores in mono- and polytherapy, variations in global cognition and in particular in memory performances were similar between monotherapy and polytherapy, although not reaching statistical significance. Overall, such findings might support the general behavior for LOEU, with the aim of treating patients with a single AED. Nevertheless, our findings might help clinicians in going for an add-on treatment, since no cognitive drawback has been delineated. Beyond global cognitive performance, we also provide evidence for a cognitive domain-specific impact of AEDs. In particular, LEV and VPA were consistently associated with an increase in verbal fluency, while VPA had a negative impact on verbal learning. Such findings might suggest a careful evaluation of LOEU treatment, eventually considering alternatives to VPA given its possible cognitive side effects [22].

To date, LOEU represents a condition without a clear etiology, and several hypotheses have been proposed in the past years. Beta amyloid, tau pathology, subtle vascular disease, and inflammation have been implicated in the etiology of LOEU [4,5]. Indeed, beta amyloid, even in the preplaque deposition stage, can alter neuronal membrane properties, triggering epileptiform activity $[23,24]$. Similarly, focal tau tangles can induce proepileptogenic changes by increasing neural spike potential [25]. Moreover, occult microvascular dysregulation and inflammatory mediators can negatively modify membrane potential and thus induce neural spiking ([26]; [27]). All the abovementioned factors might participate in the definition of the trajectory of cognitive decline among patients with LOEU. Further collaborative attempts to characterize the influence of each specific factor are needed to define driving forces for cognitive decline.

Limitations to the study can be found in the small sample size, which limits the statistical analysis, in the variety of treatments prescribed to patients and in the short follow-up needed to evaluate cognitive deterioration. However, the small sample derives from a careful selection of patients with LOEU to avoid incorrectly enrolling patients with underlying diseases producing epilepsy. Moreover, treatment choice was left up to clinicians and represented real-world practice, since the nature of the study was observational. Hence, given the inclusive design and the guidelines followed, our cohort might indeed truly reflect the population of patients with LOEU, allowing reproducibility and generalizability of results.

In conclusion, patients with LOEU are at higher risk of cognitive decline [4]. In this study, we demonstrated that patients with LOEU experienced the significant worsening in overall cognitive performances (MMSE scores) independently from number and types of prescribed AED, even within the first 12 months from diagnosis. However, the trajectory of cognition was different depending of seizure semiology and worsening exclusively in patients with FS. Hence, the etiology itself of LOEU, though elusive, might indeed play a critical role in determining the trajectory of cognitive decline for such patients. Neuropsychological assessment and careful follow-up for both epilepsy and cognition seem indicated then for patients with LOEU, which might represent an appropriate population for trials on neuroprotective treatments, especially AED.

Table 6

Neuropsychological tests at baseline and follow-up in the subgroups of patients treated by LEV, VPA, CBZ, or OXC.

\begin{tabular}{|c|c|c|c|c|c|c|c|c|}
\hline & \multicolumn{2}{|l|}{$\begin{array}{l}\operatorname{LEV}(n=12) \\
\text { mean }[S D]\end{array}$} & \multicolumn{2}{|l|}{$\begin{array}{l}\mathrm{VPA}(\mathrm{n}=9) \\
\text { mean }[\mathrm{SD}]\end{array}$} & \multicolumn{2}{|l|}{$\begin{array}{l}\mathrm{CBZ}(\mathrm{n}=9) \\
\text { mean }[\mathrm{SD}]\end{array}$} & \multicolumn{2}{|l|}{$\begin{array}{l}\mathrm{OXC}(\mathrm{n}=7) \\
\text { mean }[\mathrm{SD}]\end{array}$} \\
\hline & Baseline & FU & Baseline & FU & Baseline & $\mathrm{FU}$ & Baseline & $\mathrm{FU}$ \\
\hline MMSE & 28.17 [1.64] & $27.5[1.38]^{*}$ & 28.33 [1.58] & 28 [2.12] & 28.78 [1.79] & 28.67 [1.5] & 27.57 [2.07] & $28.29[1.70]$ \\
\hline PVF & $24.58[8.70]$ & $28.92[12.76]^{*}$ & $24.78[7.26]$ & $29[8.63]^{*}$ & 25.44 [8.63] & $25.44[5.72]$ & 26.14 [9.94] & $25.86[8.55]$ \\
\hline SVF & $32.18[5.56]$ & $34[6.08]$ & $35.56[5.22]$ & $34.22[6.32]$ & $33.56[8.86]$ & 34 [8.89] & 33.14 [10.73] & $32.71[8.12]$ \\
\hline RAVLT-I & $29.08[8.28]$ & $30.92[7.06]$ & $27.22[7.66]$ & 25.67 [9.10] & $29.89[9.24]$ & 30.33 [9.35] & 30.86 [9.37] & $29.43[10.20]$ \\
\hline RAVLT-D & $4.25[2.30]$ & $4.58[1.83]$ & $4.78[2.05]$ & $3.89[1.69]^{*}$ & $4.56[2.88]$ & $5.44[2.24]$ & $4.29[2.50]$ & $4.86[1.95]$ \\
\hline ROCF & $33.5[1.78]$ & $32.75[2.96]$ & $34.78[1.48]$ & $33.33[1.80]$ & $33.44[2.79]$ & $32.78[2.68]$ & $32[2.38]$ & 33.29 [2.87] \\
\hline
\end{tabular}

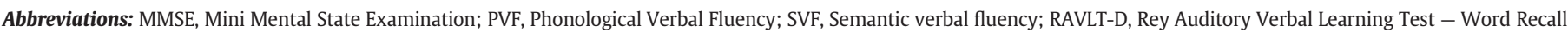
Immediate; RAVLT-D, Rey Auditory Verbal Learning Test - Word Recall Delayed; ROCF, Rey-Osterrieth Complex Figure Test; SD, standard deviation; FU, follow-up.

$* \mathrm{p}<.05$ 


\section{Declaration of competing interest}

\section{All authors have no conflict of interests.}

\section{References}

[1] Costa C, Romoli M, Liguori C, Farotti L, Eusebi P, Bedetti C, et al. Alzheimer's disease and late-onset epilepsy of unknown origin: two faces of beta amyloid pathology. Neurobiol Aging 2019;73:61-7.

[2] Hauser WA, Annegers JF, Kurland LT. Incidence of epilepsy and unprovoked seizures in Rochester, Minnesota: 1935-1984. Epilepsia 1993;34:453-8

[3] Costa C, Romoli M, Calabresi P. Late onset epilepsy and Alzheimer's disease: exploring the dual pathogenic role of amyloid- $\beta$. Brain 2018;53:467-72.

[4] Sen A, Capelli V, Husain M. Cognition and dementia in older patients with epilepsy. Brain 2018;141(6):1592-608.

[5] Costa C, Parnetti L, D'Amelio M, Tozzi A, Tantucci M, Romigi A, et al. Epilepsy, amyloid- $\beta$, and D1 dopamine receptors: a possible pathogenetic link? Neurobio Aging 2016;48:161-71.

[6] Larner AJ. Epileptic seizures in AD patients. Neuromolecular Med 2010;12:71-7.

[7] Proposal for revised clinical and electroencephalographic classification of epileptic seizures From the Commission on Classification and Terminology of the International League Against Epilepsy, Epilepsia 1981;22(4):489-501.

[8] Scheffer IE, Berkovic S, Capovilla G, Connolly MB, French J, Guilhoto L, et al. ILAE classification of the epilepsies: position paper of the ILAE Commission for Classification and Terminology. Epilepsia 2017;58:512-21.

[9] Folstein MF, Folstein SE, McHugh PR. "Mini-mental state": a practical method for grading the cognitive state of patients for the clinician. J Psychiatr Res 1975;12(3): 189-98.

[10] Jones-Gotman M, Smith ML, Risse GL, Westerveld M, Swanson SJ, Giovagnoli AR, et al. The contribution of neuropsychology to diagnostic assessment in epilepsy. Epilepsy Behav 2010;18(1-2):3-12.

[11] Carlesimo GA, Caltagirone C, Gainotti G, Nocentini U, Fadda L, Gallassi R, et al. Batteria per la valutazione del Deterioramento Mentale (parte II): standardizzazione affidabilità diagnostica nell'identificazione di pazienti affetti da sindrome demenziale. ARCHIVIO DI PSICOLOGIA, NEUROLOGIA E PSICHIATRIA. 1995;56(4):471-88.

[12] Caffarra P, Vezzadini G, Dieci F, Zonato F, Venneri A. Rey-Osterrieth complex figure: normative values in an Italian population sample. Neurol Sci 2002;22 (6): $443-7$.

[13] Rey. L'examen psycologique dans les cas d'encéphalopathie traumatique. Archives de psychologie: Les Problems; 1941.
[14] Stern RA, Singer E, Duke LM, Singer NG, Morey C, Daughtrey EW, et al. The Boston qualitative scoring system for the Rey-Osterrieth complex figure: description and interrater reliability. Clin Neuropsychol 1994;8(3):309-22.

[15] Conrad J, Pawlowski M, Dogan M, Kovac S, Ritter MA, Evers S. Seizures after cerebrovascular events: risk factors and clinical features. Seizure 2013;22:275-82.

[16] Liguori C, Izzi F, Manfredi N, D'Elia A, Mari L, Mercuri NB, et al. Efficacy and tolerability of perampanel and levetiracetam as first add-on therapy in patients with epilepsy: a retrospective single center study. Epilepsy Behav 2018;80: 173-6.

[17] Kawakami O, Koike Y, Ando T, Sugiura M, Kato H, Hiraga K, et al. Incidence of dementia in patients with adult-onset epilepsy of unknown causes. J Neurol Sci 2018;395:71-6.

[18] Vossel KA, Beagle AJ, Rabinovici GD, Shu H, Lee SE, Naasan G, et al. Seizures and epileptiform activity in the early stages of Alzheimer disease. JAMA Neurol 2013; 70:1158 66.

[19] Baker GA, Taylor J, Aldenkamp AP, SANAD group. Newly diagnosed epilepsy: cognitive outcome after 12 months. Epilepsia 2011;52(6):1084-91.

[20] Breuer LE, Boon P, Bergmans JW, Mess WH, Besseling RM, De Louw A, et al. Cognitive deterioration in adult epilepsy: does accelerated cognitive ageing exist? Neurosci Biobehav Rev 2016;64:1-11.

[21] Vossel KA, Tartaglia MC, Nygaard HB, Zeman AZ, Miller BL. Epileptic activity in Alzheimer's disease: causes and clinical relevance. Lancet Neurol 2017;16: 311-22.

[22] Romoli M, Mazzocchetti P, D'Alonzo R, Siliquini S, Rinaldi VE, Verrotti A, et al. Valproic acid and epilepsy: from molecular mechanisms to clinical evidences. Curr Neuropharmacol 2018;17.

[23] Minkeviciene R, Rheims S, Dobszay MB, Zilberter M, Hartikainen J, Fü lo“p L, et al. Amyloid beta-induced neuronal hyperexcitability triggers progressive epilepsy. J Neurosci 2009;29:3453-62.

[24] Westmark CJ, Westmark PR, Beard AM, Hildebrandt SM, Malter JS. Seizure susceptibility and mortality in mice that over-express amyloid precursor protein. Int J Clin Exp Pathol 2008;1:157-68.

[25] Palop JJ, Mucke L. Network abnormalities and interneuron dysfunction in Alzheimer disease. Nat Rev Neurosci 2016;17:777-92.

[26] Liguori C, Romigi A, Izzi F, Placidi F, Nuccetelli M, Cordella A, et al. Complement system dysregulation in patients affected by idiopathic generalized epilepsy and the effect of antiepileptic treatment. Epilepsy Res 2017;137:107-11.

[27] Emsley HCA, Parkes LM. Seizures in the context of occult cerebrovascular disease. Epilepsy Behav 2019:106396. https://doi.org/10.1016/j.yebeh.2019.06.039 [Epub ahead of print]. 